\title{
Carinal surgery: experience of a single center and review of the current literature
}

\author{
Haralabos Parissis*1 and Vincent Young²
}

\begin{abstract}
Background: To report our experience for the treatment of lung tumors of the right main bronchus (RMB) invading the carina.

Methods: From February 2000 till January 2007 we have identified 8 cases (1.09\%) requiring carinal surgery.

Plan of action: Close cooperation with anaesthetics, long flexible ET tube, Right posterolateral thoracotomy, no irrevocable steps until resection guaranteed, mobilization of trachea and main bronchus, division of the trachea \& Left main bronchus. Intubate across surgical field. Tailoring for airway size discrepancies, appropriately. Construction of the tracheobronchial anastomosis around the ventilatory tube. Skillfull reintubation, over a long boogie.
\end{abstract}

Results: Mortality: $12.5 \%$ due to ARDS (one patient)

Morbidity: anastomotic stenosis requiring stent (one patient). Follow-up $52 \pm 11$ months.

Recurrences: 2 patients (both with pathological N2 disease on histology).

Conclusions: Success of carinal surgery depends on careful patient selection, team approach and attention to detail. Patients with N2 disease carry the worst prognosis.

\section{Background}

Until recently the TNM classification staged tumours invading the carina as T4, IIIB. By implication these tumours are inoperable due to local criteria. However a subgroup of those patients can be treated by carinal resection and reconstruction with potential cure. Therefore, there is an argument that this subgroup should the staged as IIIA[1]; especially since this small group of patients consists of a potentially surgical group with favourable outcome and a five years survival up to $40 \%$ $45 \%$ [2].

Indications for carinal resection are reported [3] as: bronchogenic carcinoma (43.2\%), other airway neoplasms $(44.7 \%)$ and benign or inflammatory strictures (11.9\%).

In this report we are presenting our experience with right side carinal pneumonectomy and carina plasty. The indications, surgical steps and early outcome are reported.

*Correspondence: hparissis@yahoo.co.uk

1 Cardiothoracic Department, Royal Victoria Hospital, Belfast, Northern Ireland Full list of author information is available at the end of the article

\section{Methods}

Our series of carinal surgery consists of a small number of patients performed by a single surgeon (the senior author of the paper, VY).

From February 2000 up till January 2007 we have identified 8 cases (1.09\% of all pulmonary resections) of carinal surgery in our institution: 5 cases of right side carinal sleeve pneumonectomy (CSP) and 3 cases of carinal plasty (resection of the carina with preservation of both left and right lung).

CSP was considered when there was suitable anatomy, clinical N0, N1 disease, stump recurrence following lobectomy or positive margins after right side pneumonectomy and carcinoid/sarcoma of the carina. Written informed consent was obtained from the patients for this publication.

\section{Left carinal pneumonectomy was not encountered in this series}

The rate of false negative pre-operative $\mathrm{CT}$ evaluation of the mediastinum could be up to 35\%; moreover the sensitivity and specificity of CT staging of the mediastinal nodal involvement is 78\% [4]. For those reasons, all the 
patients in these series had undergone PET scan and mediastinoscopy (Figure 1).

Preoperative N2 disease was a contraindication for carina surgery. Therefore neoadjuvant downstaging was not considered in those series.

Brain CT in our institution is carried out only when there are clinical signs or symptoms of brain metastasis. Likewise bone scan is deemed necessary only when bone pain, hypercalcaemia or high alk phosphatase is present.

Assessment by rigid bronchoscopy and biopsy of the lower trachea/carina/right main bronchus is also carried out to further delineate the extent of the tumor involvement (Figure 2).

A favourable outcome following CSP is feasible if optimal anaesthetic and surgical strategies are to be taken into consideration.

\section{Anaesthetic strategies}

Multidisciplinary team approach and close collaboration with the anaesthetist, is required.
Long flexible Endo Tracheal (ET) tube, is used. No irrevocable steps are taken until the resection is guaranteed. Intraoperative barotrauma has to be eliminated by avoiding long periods of collapsed lung. Finally, after the posterior part of the tracheobronchial anastomosis has been constructed, skillfull reintubation over a long boogie is required.

\section{Surgical strategies}

We advocate right posterolateral thoracotomy through the $5^{\text {th }}$ intercostal space.

Mediastinal lymph node resection (stations R2, 4, 7, 8, 9) is carried out routinely in our department. The lower trachea and left main bronchus (LMB) are mobilized. The exposure is usually better facilitated, following dissection and removal of station 7 lymph nodes. Bronchial vessels in the subcarinal region are dealt with diathermia.

We use traction sutures on the lower trachea and a tape around the LMB, prior to division. Following division of the LMB, we ensure across surgical field intubation with a small size ET tube to maintain ventilation of the left lung.

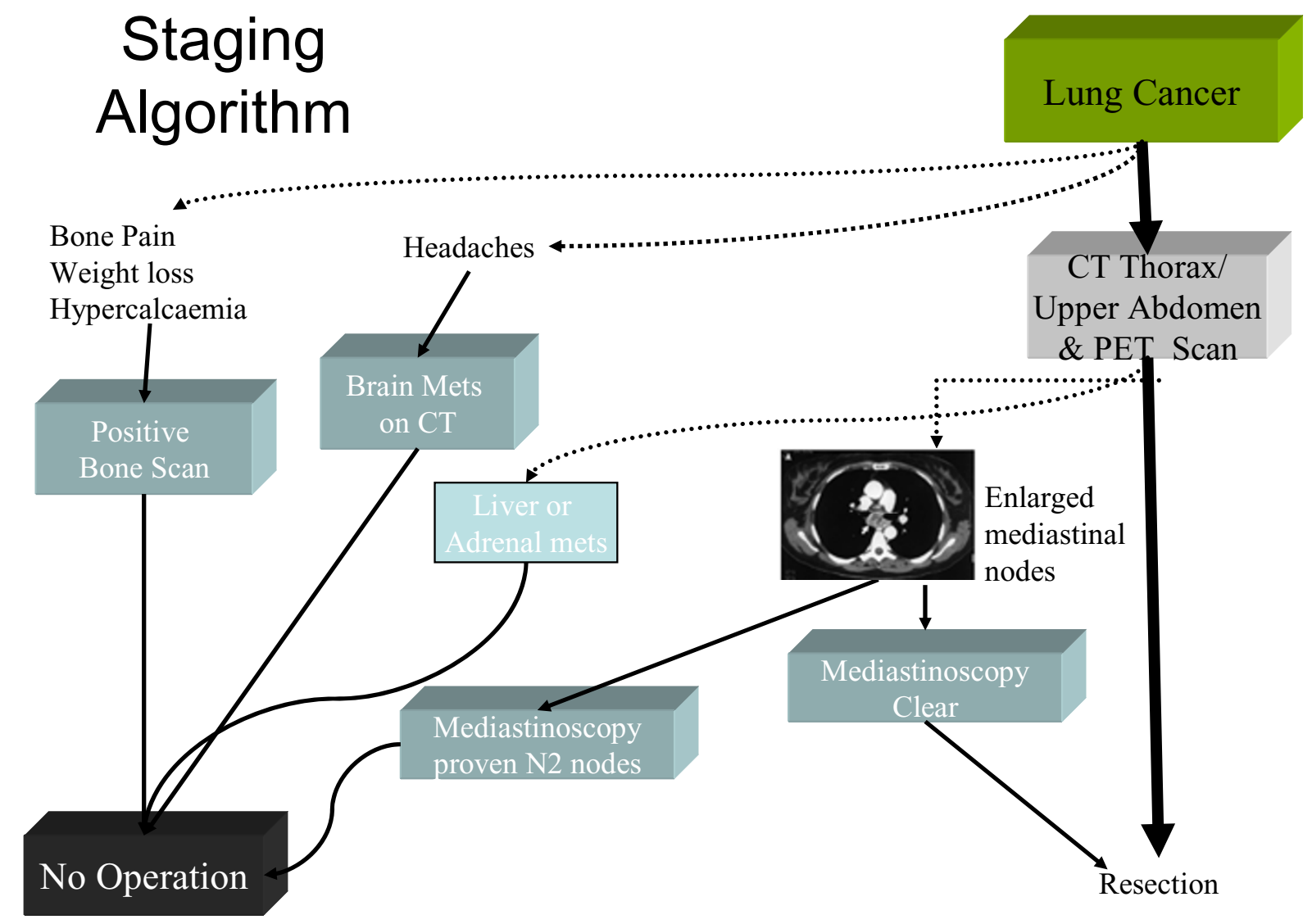

Figure 1 Staging algorithm for patients prior to carinal resection. 

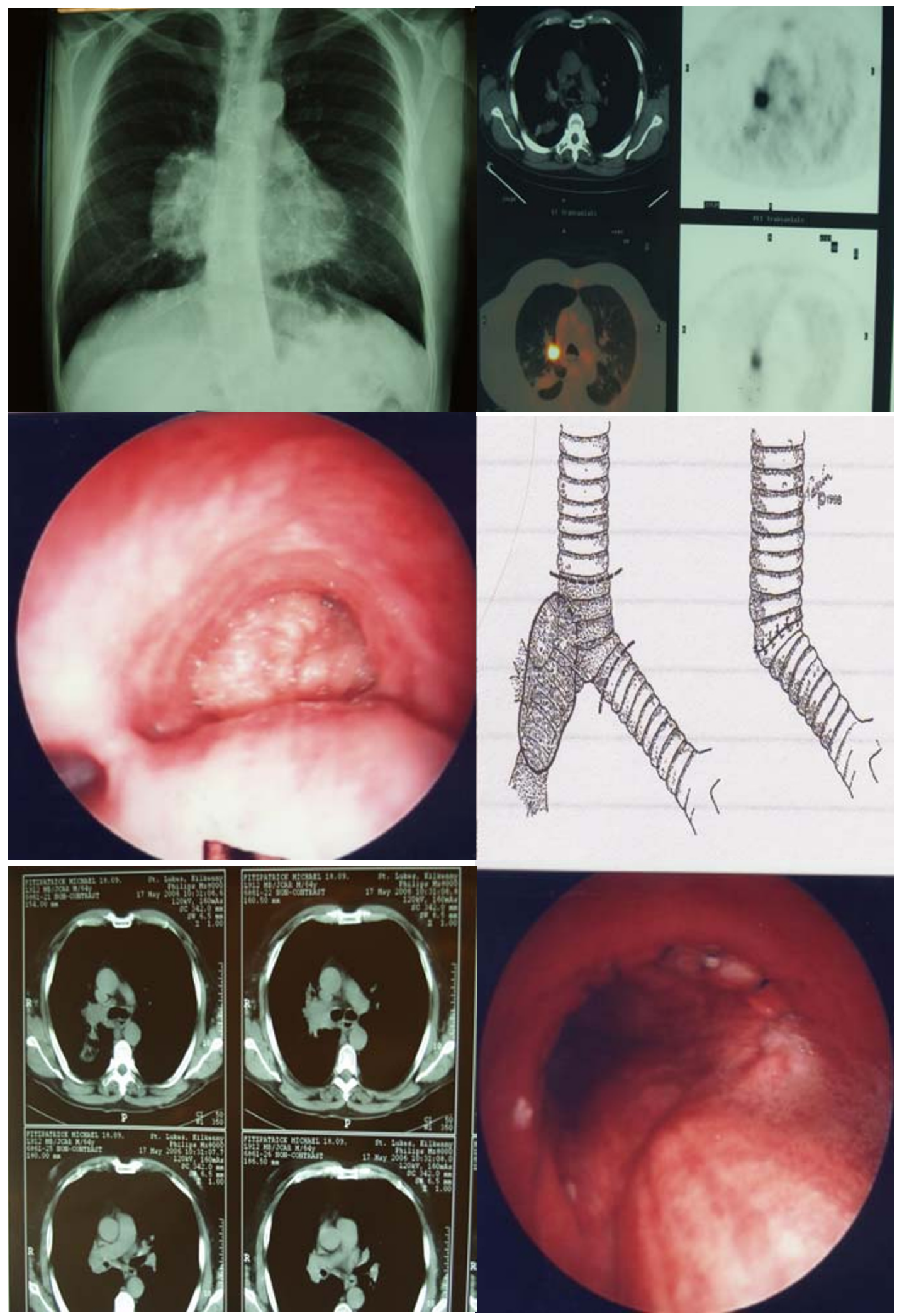

Figure 2 A case of a central Squamous cell carcinoma of the Right upper lobe invading the carina. CXR, CT Scan of the chest, PET scan, schematic representation of the tumor and Bronchoscopy before and after carinal resection showing tracheo-bronchial anastomosis. 
Frozen sections are only required if R0 resection margins are "macroscopically questionable" (none of our reported cases). Up to two tracheal rings can be removed without a danger of putting the anastomosis under tension. The construction of the end to end or end to side airway anastomosis is fashioned with a continuous 3.0 prolene. The back wall is completed first, following by endotracheal intubation across the anastomosis. The front wall is then done over the long ET tube; care must be taken to avoid "incorporating the ET tube" on the suture line. Flexible Bronchoscopic inspection of the suture line is performed routinely. Traditionally in our institution, we used prolene suture for all bronchial surgery (closure of a stump, sleeve lobectomy or bronchoplasty procedures). Discrepancies in size are less of a problem than in simple sleeve lobectomy; but where encountered were dealt with by careful adjustment of suture placement on the two airways. Telescopic anastomotic technique due to differences in size was not encountered in those series. Furthermore, we did not circumferentially wrap the anastomosis with any viable tissue (eg. Omentum or intercostal muscle).

Finally, specific release manoeuvres are not required but there is considerable mobilisation of structures due to the complete mediastinal nodal dissection performed in all patients. This is an important technical as well as oncological component of the operation.

\section{Results}

Our experience with carinal surgery, consists of 8 patients over a 7 year period. There were relative younger patients (mean age $58 \pm 3$ years) compare to the age of the overall lung resection patients $(67 \pm 8.3$ years). The patients were predominantly males with the histological diagnosis of Squamous cell Carcinoma (Table 1). One patient underwent a completion sleeve pneumonectomy: he was a 57 year old male who in a routine follow up 5 years following Right middle \& lower Lobectomy for NSCLC he was found to have collapsed of the residual lung. Bronchoscopy showed NSCLC involving the origin of the right main bronchus. He underwent a completion pneumonectomy with carinal resection. Finally, three patients underwent carinal-plasty for tracheal sarcoma or carcinoid tumours.

One patient died due to respiratory failure and ARDS two weeks following surgery. One patient developed anastomotic stenosis manifested five weeks postoperatively with stridor. He required dilatation and stenting across the anastomosis. Two patients (both with pathological N2 disease on histology) developed recurrences: patient number 2 developed local recurrences 1 year later and patient number 6 re-presented with brain metastasis 3 months after surgery.
Two patients with SCC were the long term survivors following RSP at 50 and 39 months. Finally, the only patient with the Tracheal sarcoma was alive at 29 months and the 2 patients with the carcinoid tumors were alive at 26 and 28 months of follow up.

\section{Discussion}

Pathological processes that involve the carina pose a challenge to the thoracic surgeons.

Patients must be able to withstand the procedure, and they must be told that the operative mortality is 2 to 4 times higher than what is expected after standard pneumonectomy [5]. Nevertheless, techniques have been developed to allow primary resection and reconstruction with relative moderate risk and a five year survival that does not really reflect stage IIIB disease.

Our experience refers to limited number of cases, however useful thoughtful suggestions could be derived out of it; those technically demanding operations are requiring team approach and a sound decision making process.

Maintaining optimal oxygenation through out the procedure is desirable. There are various ventilation options during construction of the airway anastomosis. Cross field ventilation is the most common used technique but requires close anaesthetic collaboration. Apnoeic oxygenation operates on the principle that with preoxygenation and hyperventilation 10-12 min of total apnea can be safely tolerated. However, due to hypoxic complications a modified technique is usually advocated whereby hyperoxygenation is followed by cross surgical field ventilation with a $10 \mathrm{~F}$ catheter and delivering $15 \mathrm{~L} / \mathrm{min} \mathrm{O} 2$. Finally, high Frequency Jet Ventilation delivered through a small bored catheter is infrequently implemented.

If the SVC is involved (up to $20 \%$ of the cases) then a brain protection strategy during concomitant SVC surgery is required. We advocate monitoring of the jugular bulb pressure (JBP) and we aim to optimise cerebral perfusion pressure by increasing the MAP at least to 60 $\mathrm{mmHg}$ above the JBP. We also aim to keep the jugular bulb oxygen saturation greater than $50 \%$. Neither venous shunt from the brachiocephalic vein to the right atrium nor neuro-protective agents and mannitole has been used by our group.

In order to achieve $\mathrm{R} 0$ resection margins, careful planning is essential. Accurate bronchoscopic biopsies along the carina are obtained; distal sides are biopsied first. Nevertheless, surgeons must always remember that it is better and safer to accept a positive resection margin than to have to deal with a bronchopleural fistula caused by anastomotic separation [5]. This is because anastomotic complications are often life-threatening [6]. The most feared complication however, is postoperative adult respiratory distress syndrome [7] encountered in up to $11 \%$ of the cases. 
Table 1: Patients characteristics

\begin{tabular}{|c|c|c|c|c|c|c|c|c|}
\hline Pt & 1 & 2 & 3 & 4 & 5 & 6 & 7 & 8 \\
\hline Age & 58 & 62 & 55 & 55 & 62 & 66 & 64 & 25 \\
\hline Sex & M & M & M & M & $\mathrm{F}$ & M & $\mathrm{F}$ & M \\
\hline Procedure & RSP & RSP & RSP & RCSP & $\mathrm{CP}$ & RSP & $\mathrm{CP}$ & $\mathrm{CP}$ \\
\hline LOS(days) & 19 & 18 & 28 & 16 & 12 & 16 & 9 & 11 \\
\hline Complications & $\begin{array}{l}\text { Chest } \\
\text { infestion }\end{array}$ & $\begin{array}{l}\text { Anastomotic } \\
\text { stenosis }\end{array}$ & ARDS & - & - & arrhytmias & - & - \\
\hline Histology & SCC & SCC & SCC & SCC & TS & SCC & Carcinoid & Carcinoid \\
\hline TNM & T4NOMO & T4N2M0 & T4N1 M0 & T4N1 M0 & No & T4N2 M0 & No & No \\
\hline Recurrence & No & Yes & No & No & No & Yes & No & No \\
\hline Status & A & A & $\mathrm{D}$ & A & A & A & A & A \\
\hline Survival (months) & $A(50)$ & $\mathrm{D}(12)$ & $D(1)$ & A (39) & $A(29)$ & $\mathrm{D}(3)$ & $A(26)$ & $A(28)$ \\
\hline
\end{tabular}

SCC: Squamous cell Carcinoma, RSP: Right Sleeve pneumonectomy, RCSP: completion sleeve pneumonectomy for T1N0 tumor removed with R middle \& lower lobectomy 5 years ago.

$\mathrm{CP}$ : carinal plasty with reinplantation of the right main bronchus to the trachea for Tracheal Sarcoma (TS) or carcinoid tumor A:Alive

D:Dead

The postoperative mortality was $12.5 \%$ in our series due to ARDS. Mitchell et al [8] reported a 20\% mortality for Carinal Pneumonectomy and $11 \%$ for carinal plasty. The overall mortality is high and this could be explained by looking at the patients characteristics (Table 2): up to $20 \%$ of the patients in those series had previous lung surgery and also up to $35 \%$ had previous chemoradiation for downstaging [9-11].

Predictors of operative mortality included postoperative mechanical ventilation, length of resected airway and development of anastomotic complications [3].

The 5 year survival (Table 2) was low in the early series [12] however late reports are quoting survival up to 44\%[11,13];Moreover Mitchell et al [3] has calculated the 5 year survival according to the pathology of the disease to be : $38 \%$ for Carinal Pneumonectomy and up to 51\% for carinal plasty. In our report out of 5 patients following CSP, there was one operative death and 2 recurrences within the first year. Two patients were intermediate survivors (e.g. alive 3-4 years later). Moreover, the 3 patients that underwent carinal plasty were still alive 2 and half years later.
Tumour recurrences are only mentioned in few reports $[10,11]$; the recurrence rate in our series was $25 \%$ but it has been quoted to be as high as 75\% [14]. Furthermore we observe a high local and distal recurrence rate in patients with pathological N2 disease; this probably outlines aggressive disease and therefore a very close follow up and post operative chemoradiation may be justified.

Nodal status Influences of the outcome according to various reports $[8,10,11,15,16]$ : patients with pathologically $\mathrm{N} 2$ disease have a $12 \% 5$ year survival versus $53 \%$ for No.

The role of neoadjuvant Chemo-Radiation therapy is debatable: According to some reports [9] it downstages $40 \%$ of $\mathrm{N} 2$ nodes therefore increases the pool of patients that they would benefit from surgical resection; However, according to other reports [17] this type of therapy should be used with caution because of the deleterious effects on anastomotic healing.

Radical lymphadenectomy is advocated in our centre routinely. This was supported by other groups. The high incidence of micrometastatic nodes in positron emission tomography-negative patients according to Macchiarini 
Table 2: Characteristics and outcome following surgery for carinal pathology

\begin{tabular}{|c|c|c|c|c|c|}
\hline Patients Characteristics $[8,9]$ & Histology $[8,10]$ & Complications $36-45 \%$ & $\begin{array}{l}\text { Concomitant } \\
\text { procedures }\end{array}$ & $\begin{array}{l}\text { Mortality Mainly } \\
\text { due to MI, ARDS, PE }\end{array}$ & $\begin{array}{l}5 \text { year } \\
\text { survival }\end{array}$ \\
\hline Predominantly males(2/3) & SCCa $70 \%-77 \%$ & Arrhythmia $18.3 \%$ & SVC Surgery $22 \%$ & $4 \%[2]$ & $15 \%[12]$ \\
\hline Previous lung surgery: $14-21.6 \%$ & AdenoCa $18 \%-20 \%$ & Anastomotic leak $16.7 \%$ & $\begin{array}{l}\text { Excision of } \\
\text { diaphragm 3\% }\end{array}$ & $15 \%[8]$ & $33.4 \%[13]$ \\
\hline Previous chemoradiation: $15-36 \%$ & Large Cell 2- 7\% & ARDS $10 \%$ & Chest wall $2 \%$ & $4 \%[9]$ & $42 \%[8]$ \\
\hline $\begin{array}{l}\text { Carinal pneumonectomy: } 58-68 \% \\
\text { Carinal Plasty: } 30 \% \text { Stump } \\
\text { revision: } 4 \%\end{array}$ & Mixed 1-3\% & Pneumonia $6.7 \%$ & LA $1 \%$ & $7.6 \%[11]$ & $44 \%[11]$ \\
\hline
\end{tabular}

References: [2,8-13]

SCCa: Squamous Cell Carcinoma

SVC: Superior Vena Cava

LA: Left Atrium

MI: Myocardial Infarction

ARDS: Adult respiratory distress Syndrome

PE: Pulmonary Embolism

et al [9] justifies routine mediastinoscopy and radical lymphadenectomy.

Finally is Sleeve pneumonectomy a justifiable procedure? The answer is negative, if the mortality rate is similar to the long-term survival and positive, if one can achieve an operative mortality under $10 \%$ and a five year survival over $20 \%$.

\section{Conclusions}

The various techniques of carinal surgery could be applied in selective cases with optimal outcome $[18,19]$.

However, success depends on careful patient selection, attention to detail and accurate preoperative staging [20].

The results reflect the technical complexity of the operation and the natural history of lung cancer but, five year survival in excess of $40 \%$ for malignant disease may be anticipated in the absence of involved mediastinal lymph nodes.

\section{Competing interests}

The authors declare that they have no competing interests.

\section{Authors' contributions}

HP participated in the sequence alignment and drafted the manuscript and $\mathrm{V}$ participated in its design and coordination. The authors read and approved the manuscript.

\section{Author Details}

${ }^{1}$ Cardiothoracic Department, Royal Victoria Hospital, Belfast, Northern Ireland and ${ }^{2}$ Cardiothoracic Department, St James Hospital, Dublin 8, Dublin, Republic of Ireland

Received: 6 March 2010 Accepted: 19 June 2010

Published: 19 June 2010
References

1. Goldstraw P, Crowley J, Chansky K, Giroux D, Groome P, Rami-Porta R, Postmus P, Rusch V, Sobin L: The IASLC Lung Cancer Staging Project:Proposals for the Revision of the TNM Stage Groupings in the Forthcoming(Seventh) Edition of the TNM Classification of Malignant Tumours. Journal of Thoracic Oncology 2007, 2:706-714.

2. Yildizeli B, Dartevelle PG, Fadel E, Mussot S, Chapelier A: Results of primary surgery with T4 non-small cell lung cancer during a 25-year period in a single center: the benefit is worth the risk. Ann Thorac Surg 2008, 86:1065-75.

3. Mitchell JD: Carinal resection and reconstruction. Chest Surg Clin N Am 2003, 13(2):315-29.

4. Vansteenkiste JF, Stroobants SG, Dupont PJ, Mortelmans LA, De Leyn PR, Verschakelen JA: Mediastinal lymph node staging with FDG-PET scan in patients with potentially operable non-small cell lung cancer: a prospective analysis of 50 cases. 1997. Chest 2009, 136(5 Suppl):

5. Deslauriers J, Grégoire J, Jacques LF, Piraux M: Sleeve pneumonectomy. Thorac Surg Clin 2004, 14:183-90.

6. Borri A, Leo F, Veronesi G, Solli P, Galetta D, Gasparri R, Petrella F, Scanagatta P, Radice D, Spaggiari L: Extended pneumonectomy for nonsmall cell lung cancer: morbidity, mortality, and long-term results. J Thorac Cardiovasc Surg 2007, 134(5):1266-72.

7. Jiang F, Xu L, Yuan F, Huang J, Lu X, Zhang Z: Carinal resection and reconstruction in surgical treatment of bronchogenic carcinoma with carinal involvement. J Thorac Oncol 2009, 4(11):1375-9.

8. Mitchell JD, Mathisen DJ, Wright CD, Wain JC, Donahue DM, Allan JS, Moncure AC, Grillo HC: Resection for bronchogenic carcinoma involving the carina:long term results and effect of nodal status on outcome. J Thorac Cardiovasc Surg 2001, 121:465-71.

9. Macchiarini P, Altmayer M, Go T, Walles T, Schulze K, Wildfang I, Haverich A, Hardin M: Hannover Interdisciplinary Intrathoracic Tumor Task Force Group. Technical innovations of carinal resection for nonsmall-cell lung cancer. Ann Thorac Surg 2006, 82:1989-97.

10. Rea F, Marulli G, Schiavon M, Zuin A, Hamad AM, Feltracco P, Sartori F: Tracheal sleeve pneumonectomy for non small cell lung cancer (NSCLC): short and long-term results in a single institution. Lung Cancer 2008, 61:202-8.

11. de Perrot M, Fadel E, Mercier O, Mussot S, Chapelier A, Dartevelle P: Longterm results after carinal resection for carcinoma: does the benefit warrant the risk? J Thorac Cardiovasc Surg 2006, 131:81-9. 
12. Jensik RJ, Faber LP, Kittle CF, Miley RW, Thatcher WC, El-Baz N: Survival in patients undergoing tracheal sleeve pneumonectomy for bronchogenic carcinoma. J Thorac Cardiovasc Surg 1982, 84:489-96.

13. Roviaro G, Vergani C, Maciocco M, Varoli F, Francese M, Despini L: Tracheal sleeve pneumonectomy: long-term outcome. Lung Cancer 2006, 52(1):105-10.

14. Jiang F, Xu L, Yuan F, Huang J, Lu X, Zhang Z: Carinal resection and reconstruction in surgical treatment of bronchogenic carcinoma with carinal involvement. J Thorac Oncol 2009, 4:1375-9.

15. Yamamoto K, Miyamoto Y, Ohsumi A, Imanishi N, Kojima F: Results of surgical resection for tracheobronchial cancer involving the tracheal carina. Gen Thorac Cardiovasc Surg 2007, 55:231-9.

16. Regnard JF, Perrotin C, Giovannetti R, Schussler O, Petino A, Spaggiari L, Alifano M, Magdeleinat P: Resection for tumors with carinal involvement: technical aspects, results, and prognostic factors. Ann Thorac Surg 2005, 80:1841-6.

17. Lanuti M, Mathisen DJ: Carinal resection. Thorac Surg Clin 2004 14:199-209.

18. Aigner C, Lang G, Klepetko W: Sleeve pneumonectomy. Semin Thorac Cardiovasc Surg 2006, 18(2):109-13.

19. Porhanov VA, Poliakov IS, Selvaschuk AP, Grechishkin AI, Sitnik SD, Nikolaev IF, Efimtsev JP, Marchenko LG: Indications and results of sleeve carinal resection. Eur J Cardiothorac Surg 2002, 22(5):685-94.

20. Liu XY, Liu FY, Wang Z, Chen G: Management and surgical resection for tumors of the trachea and carina: experience with 32 patients. World J Surg 2009, 33(12):2593-8.

doi: 10.1186/1749-8090-5-51

Cite this article as: Parissis and Young, Carinal surgery: experience of a single center and review of the current literature Journal of Cardiothoracic Surgery 2010, 5:51

Submit your next manuscript to BioMed Central and take full advantage of:

- Convenient online submission

- Thorough peer review

- No space constraints or color figure charges

- Immediate publication on acceptance

- Inclusion in PubMed, CAS, Scopus and Google Scholar

- Research which is freely available for redistribution

Submit your manuscript at www.biomedcentral.com/submit
Ciomed Central 